https:// doi.org/10.18485/iipe_nsail.2020.ch11

\author{
Jovana BLEŠIĆ ${ }^{1}$
}

\title{
ODGOVORNOST NEDRŽAVNIH AKTERA
}

Apstrakt: Nedržavni akteri dobijaju sve veći značaj $\mathrm{u}$ savremenom međunarodnom pravu, tim pre što se sve češće govori o krizi država kao subjekata međunarodnog prava. Kao učesnici u dešavanjima u okviru međunarodne zajednice snose odgovornost za akte koje počine. Odgovornost $\mathrm{u}$ međunarodnom pravu predstavlja jedan od najvažnijih instituta, te stoga ova oblast nikada ne gubi na interesovanju. I neka međunarodna tela, poput Komisije Ujedinjenih nacija za međunarodno pravo i Udruženja za međunarodno pravo, prepoznaju važnost ove teme. Pažnju ovoj temi posvećuje pre svega izveštaj specijalnog izvestioca Generalnog sekretara o potrebi za uvođenjem odgovornosti nedržavnih aktera. Zato je Komisija UN za međunarodno pravo usvojila nacrt članova o odgovornosti međunarodnih organizacija, a velika pažnja posvećena je i individualnoj krivičnoj odgovornosti. Autor će u ovom radu, pored ovih važnih pitanja, prikazati i odgovornost koju snose transnacionalne kompanije i nevladine organizacije. Cilj ovog rada je da pruži pregled aktuelnog stanja u ovim oblastima, kao i da iznese predloge za eventualne dalje poduhvate, u smislu kodifikacije.

Ključne reči: odgovornost, nedržavni akteri, međunarodne organizacije, pojedinac, oružane grupe, transnacionalne korporacije.

\footnotetext{
${ }^{1}$ Institut za međunarodnu politiku i privredu, e-mail: jovana.blesic@diplomacy.bg.ac.rs.

Rad je nastao u okviru naučnoistraživačkog projekta "Srbija i izazovi u međunarodnim odnosima 2020. godine", koji finansira Ministarstvo prosvete, nauke i tehnološkog razvoja Republike Srbije, a realizuje Institut za međunarodnu politiku i privredu tokom 2020. godine.
} 


\section{UVOD}

Sam termin odgovornost prvi put se pojavljuje u tekstovima $\mathrm{u} X \mathrm{~V}$ veku, gde se na odgovornost gleda kao na opravdanje ili odbranu pred sudom, i u XIX veku kada je označavala parlamentarnu odgovornost za nadoknadu štete $u$ okviru teorije da kralj nije odgovoran i da ne može počiniti zlo. ${ }^{2}$ Ipak, odgovornost kao pravni institut nastaje tek u XIX i XX veku. U klasičnom međunarodnom pravu nije bilo potrebe za njom jer su postojala dva načina da se spor reši: ili pregovorima ili ratom, odnosno upotrebom sile. U početku, odgovornost je bila vezana za prava stranaca i diplomatsku zaštitu. Takva situacija trajala je sve do šezdesetih godina prošlog veka. ${ }^{3}$

Na samom početku rada važno je utvrditi da je odgovornost nužna u međunarodnom pravu. Odgovornost države, na koju se prvenstveno misli kada se govori o odgovornosti, jeste osnovni princip međunarodnog prava koji proizilazi iz prirode međunarodnopravnog sistema i doktrine suvereniteta države i jednakosti država. Međunarodni protivpravni akt počinjen od strane jedne države stvara odnos sa drugom državom koji se bazira na međunarodnoj odgovornosti, a to povlači sa sobom posledicu obaveze nadoknade štete. ${ }^{4}$ Još je Stalni sud međunarodne pravde u slučaju Horzov istakao da je odgovornost princip međunarodnog prava i da kršenje bilo kakve obaveze podrazumeva obavezu naknade štete. Pravila o odgovornosti države imaju zaštitnu funkciju u međunarodnom poretku. Nazivaju se i sekundarnim pravilima. ${ }^{5}$

U prilog važnosti pravila govori i to da je odgovornost države bila među prvim temama kojima se bavila Komisija Ujedinjenih nacija za

${ }^{2}$ Volker Roeben, "Responsibility in International Law", Max Planck Yearbook of International Law, Vol. 16, 2012, p. 102.

${ }^{3}$ Robert Kolb, The International Law of State Responsibility: An Introduction, Edward Elgar Publishing Limited, Cheltenham, 2017, pp. 8-9

${ }^{4}$ Malcolm Shaw, International Law, Cambridge University Press, Cambridge, 2014, p. 566.

${ }^{5}$ Milenko Kreća, Međunarodno javno pravo, Univerzitet u Beogradu - Pravni fakultet, Centar za izdavaštvo, Beograd, 2019, str. 218. 
međunarodno pravo po svom osnivanju. Rad je započeo još 1956. godine kada je Garsija Amador bio postavljen za specijalnog izvestioca. Posao je bio dugotrajan i mukotrpan, a rezultirao je donošenjem Nacrta članova o odgovornosti država za protivpravne akte 2001. godine. Do danas ova pravila nisu stupila na snagu u obliku konvencije, ali se primenjuju kao deo običajnog međunarodnog prava. Takođe, izvršila su jak uticaj na dalji razvoj ove oblasti. On počinje sa pitanjem odgovornosti međunarodnih organizacija, pitanjem individualne krivične odgovornosti, ali i odgovornosti ostalih nedržavnih aktera, poput transnacionalnih korporacija.

Dakle, koncept odgovornosti u međunarodnom pravu počiva na odnosu primarnih i sekundarnih normi. Primarne norme su evoluirale i više nisu centralizovane samo na državu, već je jasno da mogu obavezivati i druge aktere, kao što su međunarodne organizacije, pojedinci i transnacionalne korporacije. Najveći napredak kada su u pitanju obaveze nedržavnih aktera učinjen je u polju međunarodnog krivičnog prava. Naročito kada je $u$ pitanju pojedinac koji se $u$ međunarodnom krivičnom pravu može smatrati odgovornim za neka od najtežih kršenja međunarodnog prava, čime se stvara potpuno odvojeni sistem odgovornosti. ${ }^{6}$

Kada su u pitanju transnacionalne kompanije, napredak u ovoj oblasti nije zabeležen, prvenstveno jer one nisu priznate za subjekte međunarodnog prava. Zato se $u$ ovoj oblasti više radi na različitim kodeksima ponašanja u cilju poboljšanja ljudskih i radnih prava, kao i zaštite životne sredine. Ipak, i dalje ti standardi ostaju u sferi mekog prava.

Kada su u pitanju sekundarna pravila, na prvom mestu se ističe individualna krivična odgovornost, kao i rad Komisije za međunarodno pravo na pravilima o odgovornosti međunarodnih organizacija. Međutim, razvoj sekundarnih pravila nije primećen kada su u pitanju transnacionalne korporacije. Veći napredak je ostvaren u pogledu toga da se državama pripiše odgovornost za radnje nedržavnih aktera, na

${ }^{6}$ Jutta Bruneé, "International Legal Accountability Through the Lens of the Law of State Responsibility", Netherlands Yearbook of International Law, Vol. 36, 2005, pp. 23-25. 
primer, kroz razne bilateralne i multilateralne ugovore koji omogućavaju rešavanje sporova između država i preduzeća. Takođe, pojedinci mogu da se žale na kršenje ljudskih prava u državi. ${ }^{7}$ Zanimljivo je pomenuti i Deklaraciju o pravima i odgovornosti pojedinaca, grupa i organa društva da promovišu i štite univerzalno priznata ljudska prava i osnovne slobode, kao delo Komisije za ljudska prava, koju je Generalna skupština usvojila 1998. godine. Nažalost, nije dala veće rezultate u praksi.

Pravnike koji se bave međunarodnim pravom muče različite dileme i u konceptualnom i u praktičnom smislu. Najpre, koncept odgovornosti je dizajniran prema državama i međunarodnim organizacijama. Stoga, samo određeni deo može da se primenjuje na ponašanje nedržavnih aktera koji krše međunarodno pravo. Upravo suštinski deo koncepta odgovornosti, a to je kršenje, ne može se uvek primeniti na nedržavne aktere. Najčešće su te osporavane forme ponašanja, u smislu jesu li ili nisu kršenje obaveza, kompleksne i složene jer često uključuju ponašanje i drugih aktera. Zapravo, najčešće podrazumevaju i ponašanje države. ${ }^{8}$

Međutim, ovaj rad počiva na novijem shvatanju, a to je odvajanje pojma odgovornosti od države. Pojam međunarodna odgovornost odnosi se na sve pravne subjekte $\mathrm{u}$ pravnom poretku koji će biti odgovorni za kršenja prava koja počine. Ipak, glavni argument protiv proširenja pojma odgovornosti jeste malo prakse u ovoj oblasti. Razlozi tome su višestruki. Prvo, ili se radi o novim akterima ili o onim koji su marginalni u međunarodnoj politici. Drugo, neki od njih teško mogu da izvrše neka teža kršenja međunarodnog prava. Treće, često se javljaju sudske prepreke, odnosno otežavaju sudu da dela. Četvrto, postoje praktični problemi za mnoge kolektivne aktere, poput ustaničkih ili oružanih grupa. Peto, iz praktičnih razloga mnogi se vraćaju na koncept odgovornosti države. Šesto, mnoga pitanja o odgovornosti nekih

\footnotetext{
${ }^{7}$ Ibid., pp. 27-31.

${ }^{8}$ Jean d'Aspremont, André Nollkaemper, Ilias Plakokefalos, Cedric Ryngaert, "Sharing Responsibility Between Non-State Actors and States in International Law: Introduction", Netherlands International Law Review, 62, 2015, pp. 50-51.

${ }^{9}$ Robert Kolb, The International Law of State Responsibility: An Introduction, op. cit., pp. 15-16.
} 
međunarodnih aktera rešavaju se u unutrašnjem pravu, kao što može biti slučaj sa odgovornošću pojedinca. ${ }^{9}$

U radu će biti predstavljena odgovornost međunarodnih organizacija, naizgled kodifikovana. Zatim će se govoriti o transnacionalnim kompanijama i načinima na koji one mogu biti odgovorne. Na kraju, pažnja je posvećena i pojedincu i oružanim grupama pod naslovom - Odgovornost u krivičnom i humanitarnom pravu. Čitalac će možda primetiti da nema mnogo govora o odgovornosti nevladinih organizacija. Razlog tome jeste to što se nevladine organizacije pre svega posmatraju u svetlu zaštite prava, unapređenja, pomoći u ostvarivanju prava, a jako retko kao neko ko bi mogao da prekrši pravo. Ipak, postoje neki koji ih napadaju zbog nedostatka demokratske strukture i nedostatka transparentnosti, ali nevladine organizacije i dalje uspešno izbegavaju metak odgovornosti.

\section{ODGOVORNOST MEĐUNARODNIH ORGANIZACIJA}

Kao što je već rečeno, pitanje odgovornosti blisko je povezano sa pitanjem obaveza. Pravni subjekat biće odgovoran za kršenje obaveze $u$ skladu sa pravnim sistemom. Ovaj princip se prvenstveno odnosi na države, što je potvrđeno u slučaju Chorzow Factory još 1927. godine. Iako se ovo činilo kao očigledan princip, bilo je neophodno skoro pola veka pripreme i pet specijalnih izvestilaca dok se Komisija za međunarodno pravo nije složila oko Nacrta članova o odgovornosti država 2001. godine. Međutim, kada su u pitanju međunarodne organizacije, prve su nastale u XIX veku, ali je proteklo mnogo vremena dok se nije razmatrala ideja da one mogu biti odgovorne za svoje akte. Jedan od razloga zbog kojeg je proteklo toliko vremena je verovatno to što je ograničen broj organizacija koje sprovode operativne aktivnosti kojima bi mogle da izvrše nezakonita dela. Pre svega, dugo vremena je prošlo dok

${ }^{10}$ Niels M. Blokker, "Preparing articles on responsibility of international organizations: Does the International Law Commission take international organizations seriously? A mid-term review" in: Jan Klabbers and Asa Wallendahl (eds), Research handbook on the law of international organizations, Edward Elgar Pub, Cheltenham, 2011, p. 314. 
međunarodne organizacije nisu prihvaćene kao odvojeni subjekti koji su adresari obaveza. Veza između međunarodnopravnog subjektiviteta i odgovornosti potvrđena je u savetodavnom mišljenju Međunarodnog suda pravde o Nadoknadi štete pretrpljene u službi Ujedinjenih nacija. ${ }^{10}$

Moglo bi se reći da danas postoji konsenzus oko toga da postoji princip odgovornosti međunarodnih organizacija koji počiva na nekoliko elemenata. Prvo, skoro sve međunarodne organizacije su pravni subjekti, te samim tim sposobni da snose prava i obaveze. Drugo, može se desiti da oni te obaveze prekrše i, treće, moraju da nadoknade štetu koju su pričinili. Kada se kaže da su skoro sve međunarodne organizacije pravni subjekti, misli se na to da postoje određeni izuzeci, kao što je na primer Beneluks. Obaveze koje međunarodne organizacije imaju zavise od njihovih funkcija i moći. Često su te funkcije ograničene i samim tim je ograničena mogućnost da budu odgovorne. ${ }^{11}$

Razlozi zbog kojih je došlo do razvoja oblasti odgovornosti međunarodnih organizacija su sledeći. Najpre, međunarodne organizacije mnogo više koriste svoje moći od kraja Hladnog rata, razvijala se opšta klima odgovornosti, kao i mogućnost da se sačini nacrt članova od kada je Komisija za međunarodno pravo završila rad o odgovornosti država 2001. godine. Na samom početku rada bilo je logično da će se Komisija osloniti na nacrt članova o odgovornosti države, uzevši taj nacrt kao početnu tačku. Zapravo, činilo se da su pravila za države dovoljno opšta da mogu da se primene i na međunarodne organizacije, a to bi onda značilo da postoje koherentna pravila o međunarodnoj odgovornosti. Istovremeno, bilo je jasno da Komisija ima pristup kojim želi da dozvoli izmene u skladu sa specifičnom prirodom međunarodnih organizacija. Od samog početka rada, Komisija je imala poteškoća sa pronalaskom relevantne prakse jer nije imala dovoljno informacija. Zbog toga se takođe ne može proceniti da li se ovi članovi o odgovornosti međunarodnih organizacija mogu odnositi na sve. ${ }^{12}$

\footnotetext{
${ }^{11}$ Ibid., p. 315.

${ }^{12}$ Ibid., pp. 318-320.
} 
Međunarodne organizacije definitivno nisu države. Još je 1949. godine Međunarodni sud pravde, u svom savetodavnom mišljenju, prepoznao međunarodne organizacije kao subjekte međunarodnog prava, ali i zapazio da subjekti prava ne moraju nužno imati iste obaveze i da njihova priroda zavisi od potreba zajednice. ${ }^{13}$

Osnovno pitanje bilo je da li Komisija za međunarodno pravo zaista može da uzme nacrt članova o odgovornosti države kao početnu tačku za stvaranje nacrta o odgovornosti međunarodnih organizacija. Prilikom izrade nacrta, Komisija je 2002. godine postavila profesora Gaju, italijanskog člana, za specijalnog izvestioca. On je odmah zauzeo stav da rad Komisije mora biti koherentan, te da se nacrt o odgovornosti međunarodnih organizacija može oslanjati na nacrt članova o odgovornosti države, što ne znači da se one nužno izjednačavaju. Mnogim međunarodnim organizacijama se ovaj pristup nije dopao, te su izražavale zabrinutost za samu metodologiju Komisije. Naime, Komisija bazira svoj rad na veoma ograničenoj praksi i ne obraća dovoljno pažnju na specifičnosti međunarodnih organizacija. ${ }^{14}$

Komisija za međunarodno pravo usvojila je 2011. godine Nacrt članova o odgovornosti međunarodnih organizacija, kao nastavak ranijeg rada Udruženja za međunarodno pravo koje je 2004. godine usvojilo set preporučenih pravila i prakse o odgovornosti međunarodnih organizacija. Nacrt Komisije može da posluži u situacijama kada organizacija prekrši obaveze prema državama ili prema drugim organizacijama, ali problem nastaje u onim mnogo češćim situacijama, a to je onda kada vrši svoje javne moći. ${ }^{15}$

Javile su se ozbiljne kritike na ovaj nacrt. Pre svega, kritikovano je to što je praćen model o odgovornosti država, zatim to što je slabo obraćana

${ }^{13}$ Alain Pellet, “International Organizations Are Definitely Not States. Cursory Remarks on the ILC Articles on the Responsibility of International Organizations" in: Maurizio Ragazzi (ed.), Responsibility of International Organizations, Essays in Memory of Sir Ian Brownlie, Martinus Nijhoff Publishers, Leiden, Boston, 2013, p. 42.

${ }^{14}$ Ibid., pp. 43-45.

${ }^{15}$ Jan Klabbers, "Issues of responsibility", chapter in An Introduction to International Organizations Law, Cambridge, Cambridge University Press, 2015, p. 315. 
pažnja na razlike između različitih organizacija, kao i to da nema potporu u praksi. ${ }^{16}$

Jedna od najvećih kritika jeste da nacrt članova iz 2011. godine nije posvetio dovoljno pažnje principu specijalnosti, koje je zajedno sa doktrinom o implicitnim moćima jedan od osnovnih stubova statusa međunarodnih organizacija. Princip specijalnosti znači da, za razliku od država koje imaju opšta ovlašćenja, međunarodne organizacije imaju ograničene funkcije u zavisnosti od interesa koje promovišu. Međutim, nijedna kritika nije dala predlog kako uvrstiti princip specijalnosti u nacrt članova. ${ }^{17}$

Jedna od kritika odnosi se i na ograničenu pažnju koja je posvećena međunarodnim organizacijama i obavezi kompenzacije. Komisija za međunarodno pravo ovde nije uspela da nađe zadovoljavajući balans između odgovornosti i načina na koji se ta odgovornost implementira na žrtve. U konačnoj verziji nacrta rečeno je da će odgovorna međunarodna organizacija preduzeti sve prikladne mere u skladu sa pravilima kako bi osigurala da će njeni članovi efektivno izvršavati obaveze. ${ }^{18}$

Kao što je rečeno, ovi članovi se umnogome oslanjaju na nacrt članova o odgovornosti država, i po pitanju sadržajnog i proceduralnog dela, što je dovelo do negativnih reakcija.

Kada je u pitanju sadržajni deo, najpre se ističe da su pravila o odgovornosti i države i međunarodnih organizacija sekundarna, za razliku od primarnih pravila, koja se nalaze u osnivačkim ugovorima i ugovorima koje zaključuju države i međunarodne organizacije. Pravila o odgovornosti međunarodnih organizacija zasnovana su na mnogo manje prakse nego pravila o odgovornosti država, zato su pravila $u$ velikoj meri zasnovana na članovima o odgovornosti država. Sto se tiče proceduralnog dela i tu su u velikoj meri slični. Sudovi i tribunali nisu imali mnogo prilika da primene pravila nacrta članova, jer se čak dve

\footnotetext{
${ }^{16}$ Ibid., p. 316.

${ }^{17}$ Alain Pellet, "International Organizations Are Definitely Not States. Cursory Remarks on the ILC Articles on the Responsibility of International Organizations", op. cit., pp. 46-48.

${ }^{18}$ Ibid., pp. 49-51.
} 
trećine sporova vezanih za međunarodne organizacije rešava mehanizmom za rešavanje sporova koji rešava treća strana. ${ }^{19}$

Dva osnovna principa Nacrta pravila o odgovornosti međunarodnih organizacija su da međunarodne organizacije jesu autonomni subjekti međunarodnog prava i time preuzimaju odgovornost za svoje akte i princip da bi trebalo da bude dostupno određeno pravno sredstvo za pojedince koji su povređeni radnjom međunarodne organizacije. ${ }^{20}$

Opšte je zastupljeno mišljenje da međunarodne organizacije imaju odvojenu međunarodnopravnu ličnost od svojih država članica. Princip koji je prihvaćen jeste da države članice ne mogu da se smatraju odgovornim za radnje međunarodnih organizacija samo na osnovu toga što su njihove članice. To proizilazi i iz komentara Komisije za međunarodno pravo na član 62 Nacrta pravila o odgovornosti međunarodnih organizacija. Jedini slučaj kada bi država članica mogla biti odgovorna jeste onda kada je na neki način uticala na akt međunarodne organizacije, npr. saradnja, pomoć, kontrola, saučesništvo itd. ${ }^{21}$

Jedan od najboljih mehanizama za utvrđivanje odgovornosti država za kršenje ljudskih prava jeste Evropski sud za ljudska prava. Ovaj sud je u nizu slučajeva utvrdio da kada države članice Evropske konvencije o ljudskim pravima formiraju međunarodnu organizaciju, one ne preuzimaju odgovornost na osnovu konvencije za radnje same organizacije. Nacrt članova o odgovornosti međunarodnih organizacija je kritikovan iz različitih perspektiva, ali može da posluži kao vodič i da pomogne u utvrđivanju odgovornosti pod kojima države članice mogu biti odgovorne za radnje svojih organizacija. $U$ te svrhe se mogu tumačiti i odluke i presude Evropskog suda za ljudska prava. Važno je

${ }^{19}$ Kristina Daugirdas, "Reputation and the Responsibility of International Organizations", The European Journal of International Law, Vol. 25, no. 4, 2014, pp. 994-997.

${ }^{20}$ Cedric Ryngaert, “The European Court of Human Rights'approach to the Responsibility of Member States in connection with acts of International Organizations", International and Comparative Law Quarterly, Vol. 60, No. 4, p. 999. ${ }^{21}$ Ibid. 
napomenuti da ni pristup Komisije za međunarodno pravo niti Evropskog suda ne predstavlja nužno opšte međunarodno pravo. ${ }^{22}$

Akteri u međunarodnom pravu mogu se smatrati odgovornim i za počinjene radnje, ali i za propuštanja. Tako, član 4 Nacrta članova o odgovornosti međunarodnih organizacija kaže da postoji međunarodni protivpravni akt onda kada se akt sastoji iz delovanja ili propuštanja i pripisiv je međunarodnoj organizaciji i krši obavezu koju ona ima. ${ }^{23}$

Propuštanje međunarodne organizacije, o kojem se najviše diskutuje, jeste odbijanje Ujedinjenih nacija da intervenišu za genocid u Ruandi. U aprilu 1994. godine preko 800.000 ljudi je ubijeno, o čemu su Ujedinjene nacije bile obaveštene da se može desiti, ali nisu reagovale. Mora se napomenuti da ne postoji jasna pravna obaveza da Ujedinjene nacije moraju intervenisati $u$ takvim stvarima, i da postoje neka svedočenja da su Ujedinjene nacije delale $u$ teškim uslovima i da su imale mnogo prepreka.

Teško je reći da je učinjen međunarodni protivpravni akt na osnovu Povelje Ujedinjenih nacija, jer ona samo daje mogućnost Ujedinjenim nacijama, tj. Savetu bezbednosti da interveniše, ali ne nameće obavezu. Zato izvor ove obaveze možda treba poražiti u opštim principima međunarodnog prava ili običajima. Tako, na primer, zaključujemo da je Konvencija o genocidu postala sastavni deo običajnog prava koji stvara obaveze za celu međunarodnu zajednicu da spreče i kazne, a te norme su i jus cogens. Na taj način, Ujedinjene nacije bi mogle biti odgovorne jer nisu sprečile genocid u Ruandi. Međutim, tom logikom bi sve međunarodne organizacije mogle biti odgovorne za neintervenciju. ${ }^{24}$

${ }^{22}$ Cedric Ryngaert, “The European Court of Human Rights'approach to the Responsibility of Member States in connection with acts of International Organizations", International and Comparative Law Quarterly, Vol. 60, No. 4, pp. 997-1016; doi: 10.1017/S0020589311000467.

${ }^{23}$ Draft articles on the responsibility of international organizations, Yearbook of the International Law Commission, 2011, vol. II, Part Two, Article 4.

${ }^{24}$ Jan Klabbers, "Reflections on Role Responsibility: The Responsibility of International Organizations for Failing to Act", The European Journal of International Law, Vol. 28, no. 4, p. 1138; 1142; 1144. 


\section{ODGOVORNOST TRANSNACIONALNIH KOMPANIJA}

Sam naziv ovih nedržavnih aktera pokazuje nam da se radi o izuzetnoj moći, jer delaju u više od jedne države. Samim tim povećana je mogućnost da dođe do kršenja ljudskih prava, na primer, zapošljavanjem dece, diskriminacijom zaposlenih, obezbeđivanjem nezdravih uslova za rad, ali i stvaranjem otrovnog otpada. ${ }^{25}$

Uticaj globalizacije zaslužan je za sve veću ulogu transnacionalnih korporacija u međunarodnom pravu. Pravo se razvija zajedno sa globalizacijom, a u tome sekundarni izvori imaju ključnu ulogu. Tako nastaje i novi lex mercatoria, odnosno transnacionalno pravo ekonomskih transakcija. Horizontalni efekat ljudskih prava ima ključnu ulogu u doba globalizacije. Ovaj efekat izražava sposobnost normi ljudskih prava da utiču na sferu odnosa između privatnih aktera, osim veze između države i privatnih aktera, što predstavlja vertikalni efekat. Upravo od ovog horizontalnog efekata zavisiće i to da li transnacionalne korporacije imaju obaveze i da li mogu biti odgovorne. ${ }^{26}$

Poslednjih godina, $\mathrm{u}$ zemljama $\mathrm{u}$ razvoju, javlja se koncept korporativne socijalne odgovornosti. On podrazumeva da su korporacije obavezne ne samo da maksimizuju interese svojih učesnika, da ograniče negativne aspekte svojih radnji i da poštuju pravo, već i da doprinesu socijalnom razvoju i da izađu u susret interesima šireg spektra učesnika. $\mathrm{U}$ ovoj oblasti je veoma značajno meko pravo, naročito u zemljama $\mathrm{u}$ razvoju gde domaće pravo često ne prepoznaje ljudska prava i gde instrumenti međunarodnog prava možda ne bi imali efekta. Glavni instrument mekog prava u ovoj oblasti jesu Norme Ujedinjenih nacija o odgovornosti transnacionalnih korporacija i drugih poslovnih preduzeća $\mathrm{u}$ odnosu na ljudska prava, kao i neki instrumenti Međunarodne organizacije rada. ${ }^{27}$ Korporativna socijalna odgovornost nekome bi

${ }^{25}$ David Weissbrodt, "Roles and Responsibilities of Non-State Actors" in: Dinah Shelton (ed), The Oxford Handbook on International Human Rights Law, pp. 561-562.

${ }^{26}$ Elena Pariotti, "International Soft Law, Human Rights and Non-state Actors: Towards the Accountability of Transnational Corporations?", Human Rights Review, 10, p. 142.

${ }^{27}$ Ibid., pp. 143-145. 
mogla delovati kao opasnost koja može da skrene pažnju menadžmenta sa maksimizacije vrednosti. Mnogi na vodećim pozicijama $u$ kompanijama danas idu alternativnim putem, jer se slažu sa ovim konceptom i da bi izbegli negativnu sliku kod svojih potrošača. ${ }^{28}$ Nevladine organizacije se mogu pokazati kao advokati, učesnici ili savetnici u ovom postupku. Upravo zbog porasta svog uticaja, nevladine organizacije mogu dati novu dimenziju korporativnoj odgovornosti. ${ }^{29}$

Za transnacionalne kompanije karakteristični su kodeksi ponašanja koji postoje još od sedamdesetih godina XX veka, s tim što je danas u porastu trend samoregulacije, kako bi sprečili nametanje. Ipak, veliki problem kod ovih kodeksa jeste sistem nadzora nad sprovođenjem, te je zato njihova efikasnost zapravo slaba. ${ }^{30}$

Kada kompanije direktno ili indirektno krše ljudska prava one stvaraju poslovni rizik, koji može da se odrazi u postojećoj praksi, vezi ili situaciji gde je kompanija vezana za kršenje ljudskih prava. To može firmu koštati mnogo toga - na primer, reputacije, rizika i gubitka poverenja investitora i potrošača. Stoga, firme traže način da spreče potencijalne rizike vezane za kršenje ljudskih prava. Tako je profesor Džon Rugi, specijalni izvestilac Generalnog sekretara za ljudska prava i transnacionalne korporacije i druga poslovna preduzeća, razvio Vodeće principe u biznisu i ljudskim pravima. Godine 2005, tadašnji Generalni sekretar Ujedinjenih nacija, Kofi Anan, imenovao je Džona Rugija za specijalnog izvestoca u ovoj oblasti. Posao nije bio lak. Nakon nekoliko godina i sprovedenih ispitivanja, 2008. godine Rugi je razvio okvirnu osnovu, 2010. godine sačinio nacrt Vodećih principa, i konačnu verziju sa komentarima objavio je 2011. godine. Dakle, izvršioci bi trebalo da vode računa o ljudskim pravima sa dužnom pažnjom (,due diligence $\left.{ }^{\prime \prime}\right)$ i da

${ }^{28}$ Terrence Guay, Jonathan P. Doh, Graham Sinclair, “Non-governmental Organizations, Shareholder Activism, and Socially Responsible Investments: Ethical, Strategic, and Governance Implications", Journal of Business Ethics, 52, p. 128.

${ }^{29}$ Ibid., p. 136.

${ }^{30}$ August Reinisch, "The Changing Internantional Legal Framework for Dealing with Non-State Actors", in: P. Alston (ed), Non-State Actors and Human Rights, Oxford, Oxford University Press, 2005, pp. 43-48; 52. 
obezbede povređenoj strani pristup pravnom leku. Ovi vodeći principi su jedna vrsta hibrida, povezuju obaveze vlade u pogledu ljudskih prava sa dobrovoljnim poslovnim incijativama. Ipak, smatra se da ovi principi nisu dovoljno poznati i shvaćeni. Zapravo, jako mali broj privrednih društva i nevladinih organizacija jeste učestvovao u njihovom kreiranju. Na kraju, važno je napomenuti i da veliki deo poslovnog sveta smatra da je ovo preskupo i da sama implementacija ovih principa troši previše vremena. Ovi principi svakako da predstavlju jednu inovaciju, transparentni napor da se razjasni odgovornost za ljudska prava $u$ poslovanju. Nužno je napomenuti da su vlade i korporacije uradile vrlo malo kako bi implementirale ove principe. Dve najveće i ključne praznine $\mathrm{u}$ ovim principima su to da prvo ne razmatraju važnu ulogu poslovanja u plaćanju poreza i u tim slučajevima „ponašanje dobrog građanina“, a drugo, to što Rugi nikada nije dobio mandat da izgradi javni slučaj za poslodavce da poštuju ljudska prava i time je javnost ostala neobaveštena. ${ }^{31}$ Pored ovog akta, važno je pomenuti i Globalni sporazum (Global Compact) koji je u januaru 1999. godine predložio Generalni sekretar Ujedinjenih nacija Kofi Anan, kao sporazum o zajedničkim vrednostima i principima na Svetskom ekonomskom forumu u Davosu. ${ }^{32}$

Postoje tri koncepcije koje se zasnivaju na savremenoj praksi zaštite ljudskih prava. Prvi koncept se naziva trihotomija, jer počiva na tri nivoa: poštovanje, zaštita i ispunjenje. Cilj je da vlada spreči nedržavne aktere $\mathrm{u}$ povređivanju drugih u domaćem kontekstu. Druga koncepcija je skorija i realizacija je rada Komiteta za intervenciju i državni suverenitet iz devedesetih godina, a kasnije je razvijana u formi Responsibility to Protect. Ova koncepcija se u osnovi svodi na intervenciju, najčešće $u$ vojnom obliku, koja je neophodna kako bi se građani jedne zemlje zaštitili od povreda ljudskih prava koje im nanosi njihova vlada. Treća koncepcija

${ }^{31}$ Susan Ariel Aaronson and Ian Higham, "Putting the Blame on Governments: Why Firms and Governments Have Failed to Advance the Guiding Principles on Business and Human Rights", in Kurt Mills and David Jason Karp (eds), Human Rights Protection in Global Politics, Palgrave Macmillan, London, 2015, p. 115, p. 119 , p. 129.

${ }^{32}$ David Weissbrodt, "Roles and Responsibilities of Non-State Actors", op. cit., p. 563. 
pak smatra da je dužnost zaštite zapravo izvedena iz odgovornosti za ljudska prava. ${ }^{33}$

Vodeći principi, koje je kreirao Rugi, svode se na zaštitu, poštovanje i pomoć kada su u pitanju ljudska prava. Radi se o tome da korporativna odgovornost zapravo predstavlja moralnu dužnost ne nanositi zlo drugome i njegovim pravima. Međutim, vodeći principi proširuju ovu dužnost sa negativne obligacije na pozitivnu, $u$ smislu uvođenja raznih obaveza kroz koje bi se "due diligence" ispoljio. ${ }^{34}$

U XX veku došlo je do rasta uticaja i domašaja korporacija i drugih nedržavnih aktera u svakoj sferi kako domaćeg života, tako i međunarodnih odnosa. Sa proliferacijom nemeđunarodnih oružanih sukoba, broj i raznovrsnost organizovanih entiteta stalno raste. Žalbeni panel Specijalnog tribunala za Lebanon je 2014. godine utvrdio da je korporativna krivična odgovornost na ivici da postane opšti princip međunarodnog prava, a dve godine kasnije postao je prvi međunarodni tribunal $\mathrm{u}$ istoriji koji je jednu korporaciju okrivio za krivično delo i odredio novčanu kaznu.

Zanimljivo je kako je žalbeni panel doneo ovu odluku. S obzirom na to da ne postoji potpora $u$ običajnom pravu, sud je svoju odluku zasnovao na drugi način. Prvo je ispitivao međunarodne standarde ljudskih prava, kao i nacionalne zakone, zatim je razmatrao opšte principe međunarodnog krivičnog prava i procedure, i tako pronašao vezu između opštih principa odgovornosti korporacija i potencijala pravnog subjekta da bude krivično odgovoran. ${ }^{35}$

${ }^{33}$ David Jason Karp, "The Concept of Human Rights Protection and the UN Guiding Principles on Business and Human Rights", in Kurt Mills and David Jason Karp (eds), Human Rights Protection in Global Politics, Palgrave Macmillan, London, 2015, pp. 137-138.

${ }^{34}$ Ibid., pp. 148-150.

${ }^{35}$ Ilya Nuzov, "Post-Conflict Justice: Extending International Criminal Responsibility to Non-State Entities" in: Ezequiel Heffes, Marcos D. Kotlik, Manuel J. Ventura (eds), International Humanitaran Law and Non-State Actors, The Hague, Springer, 2020, pp. 233-235. 


\section{ODGOVORNOST U KRIVIČNOM I HUMANITARNOM PRAVU}

Kada je u pitanju domaće pravo, do kraja prve decenije XXI veka, svi domaći pravni sistemi su poznavali neku formu odgovornosti nekog od nedržavnih aktera ili putem krivičnih ili raznih regulatornih i administrativnih kodeksa. Brojni su i međunarodni i regionalni ugovori koji se bave krivičnom odgovornošću nedržavnih aktera. Njih možemo svrstati u četiri kategorije. Prva i najređa jeste ona koja ponašanje nedržavnih aktera direktno kriminalizuje. Drugu grupu čine ugovori koji zahtevaju od država potpisnica da kriminaliziju ponašanje nedržavnih aktera, naročito kada su u pitanju finansijska krivična dela. Treća kategorija sastoji se od ugovora koji samo implicitno govore o odgovornosti nedržavnih aktera. Na kraju, tu su oni ugovori koji nameću obaveze nedržavnim akterima da ne krše međunarodno humanitarno pravo niti ljudska prava, ali ne kriminalizuju kršenja.

Komisija za međunarodno pravo odlučila se da ne kriminalizuje ponašanje ni države ni međunarodnih organizacija. I Savet bezbednosti i Generalna skupština Ujedinjenih nacija su više puta utvrđivali ozbiljna kršenja međunarodnog humanitarnog prava počinjena od strane organizovanih nedržavnih aktera, uglavnom ih oslovljavajući sa „učesnici u zločinu“. Jedna od najznačajnih je Rezolucija 2170 Saveta bezbednosti koja se naročito odnosi na nedržavne aktere i priznaju mogućnost da oni direktno krše međunarodno humanitarno pravo. Važno je pomenuti i Savet za ljudska prava Ujedinjenih nacija i usvajanje Vodećih principa za biznis i ljudska prava. ${ }^{36}$

Kada je u pitanju međunarodno humanitarno pravo često se pominje zajednički član 3 Zenevskih konvencija iz 1949. godine, koji je usmeren na svaku stranu u sukobu i ovaj član se primenjuje na sukobe koji nisu međunarodnog karaktera. To bi moglo da znači da ugovori moraju imati odredbu koja direktno obavezuje nedržavne oružane grupe. Problem se javlja u tome što ugovori obavezuju samo ugovorne strane, a Ženevske konvencije i slični ugovori humanitarnog prava nisu otvoreni za potpisavanje nedržavnih oružanih grupa. Izuzetak od opšteg pravila

${ }^{36}$ Ibid., pp. 245-246. 
jeste situacija kada treća strana pristane da bude obavezana konkretnim ugovorom, kao i član 96 Prvog dodatnog protokola uz Ženevsku konvenciju iz 1977. godine koji dozvoljava određenim oružanim nedržavnim akterima (poznatijim kao narodni oslobodlački pokreti) da mogu da primene Protokol i konvenciju na određeni sukob. Ipak, ne smemo zaboraviti da je zajednički član 3 Ženevskih konvencija stekao univerzalne razmere i postao deo običajnog prava. I Međunarodni sud pravde je u slučaju Nikaragva v. SAD to primetio. Iako postoje još neki ugovori koji se odnose, ili bi mogli da se odnose, na naoružane nedržavne aktere, nije jasno na koji način ih oni obavezuju. Zato je veoma važno običajno međunarodno pravo. ${ }^{37}$

Kada je u pitanju međunarodno krivično pravo mora se govoriti o komandnoj odgovornosti, odnosno superiornoj odgovornosti odgovornih komandanata oružanih nedržavnih aktera. Kada oružana nedržavna grupa zadovolji uslove da se primeni humanitarno pravo na osnovu postojanja oružanog sukoba, postojaće i odgovorni komandanti. Ti komandanti biće krivično odgovorni za ratne zločine koje su učinili njihovi potčinjeni pod određenim uslovima, a mogu biti odgovorni i jer ih nisu sprečili. ${ }^{38}$

Nakon Drugog svetskog rata, postojanje individualne krivične odgovornosti za ratne zločine je jako brzo potvrđeno, ali su tačni parametri ostali nedefinisani. $U$ razvoju individualne krivične odgovornosti, najveći doprinos dali su ad hoc međunarodni tribunali sa svojim dokumentima i predstavljanjem običajnog prava, naročito kada je u pitanju komandna odgovornost. ${ }^{39}$

Od svih nedržavnih aktera jedino pojedinci mogu da snose međunarodnu krivičnu odgovornost za ozbiljna kršenja međunarodnog

${ }^{37}$ Andrew Clapham, "The Rights and Responsibilities of Armed Non-State Actors: The Legal Landscape \& Issues Surrounding Engagement", dostupno na SSRN: https:/ / ssrn.com/abstract=1569636. ili http:/ / dx.doi.org/10.2139/ssrn.1569636, 10/05/2020, p. 6.

${ }^{38}$ Ibid., p. 34.

${ }^{39}$ Shane Darcy, "Assistance, direction and control: Untangling international judicial opinion on individual and State responsibility for war crimes by non-State actors", International Review of the Red Cross, Vol. 96, p. 247. 
humanitarnog prava. Ova odgovornost vodi poreklo od odgovornosti pojedinca za pirateriju i genocid, i tako je postala sastavni deo običajnog prava. ${ }^{40}$ Još od Tribunala u Nirnbergu i Tokiju, preko ad hoc tribunala, pa do Međunarodnog krivičnog suda, gonjenje i kažnjavanje pojedinaca je jedina forma krivične sankcije za ratne zločine i druge zločine međunarodnog krivičnog prava. Ipak, ratni zločini, genocid i zločin protiv humanosti su zločini koji se sprovode kolektivno. Kolektivni entiteti, pored države, zapravo su učesnici u kršenju međunarodnog humanitarnog prava i ljudskih prava, a ipak ne snose direktnu odgovornost. ${ }^{41}$

Član 9 Nacrta članova o odgovornosti države za protivpravne akte kaže da će se ponašanje osobe ili grupe osoba tumačiti kao radnja države prema međunarodnom pravu ukoliko ta osoba ili grupa zapravo sprovodi elemente vlasti u odsustvu zvaničnih vlasti i u okolnostima koji na to pozivaju. ${ }^{42}$ Prema opštem pravilu o odgovornosti države, one nisu odgovorne za radnje oružanih grupa, već samo za radnje onih organa ili pojedinaca koji su delovali pod njenim uputstvom ili kontrolom, tzv. agenti. Član 10 Nacrta kaže da opšti princip u odnosu na ponašanje takvih pokreta, počinjen tokom oružane borbe za uspostavljenom vlašću nije pripisiv državi prema međunarodnom pravu. ${ }^{43}$ Ipak, i od ovog pravila postoje izuzeci - najpre to da će država biti odgovorna za ponašanje ustaničkih grupa koje je bilo uspešno u svom pokušaju da preuzmu vlast, ili ponašanje ustaničkih grupa koje je dovelo do stvaranja nove države na delu teritorije stare države. Tri uslova za primenu člana 9 su: 1) osoba ili grupa mora zapravo sprovoditi elemente vlasti, 2) u odsustvu zvaničnih vlasti, i 3) u okolnostima koji pozivaju na primenu tih elemenata vlasti. Mora se prilikom tumačenja uzeti u obzir da član 9

\footnotetext{
${ }^{40}$ Robert McCorquodale, "The Individual and the International Legal System" in: Malcom Evans (ed), International Law, Oxford, Oxford University Press, 2006, p. 314.

${ }^{41}$ Ilya Nuzov, "Post-Conflict Justice: Extending International Criminal Responsibility to Non-State Entities", op. cit., pp. 249-250.

${ }^{42}$ Draft Articles on Responsibility of States for Internationally Wrongful Acts, Yearbook of the International Law Commission, 2001, vol. II (Part Two), Article 9.

${ }^{43}$ Ibid., Article 10.
} 
uopšte ne pominje oružane grupe, ali je ta ideja bila pomenuta tokom diskusija u radu Komisije za međunarodno pravo. ${ }^{44}$

Komisija za međunarodno pravo, Međunarodni sud pravde i Međunarodni krivični tribunal za bivšu Jugoslaviju su razmatrali problem odgovornosti države za radnje nedržavnih aktera u kontekstu oružanih sukoba. Svi su imali problem u rešavanju ovog pitanja. Na prvom mestu, problem su imali zbog različitog pristupa dilemi odgovornosti države. Veliki problem predstavlja to što svi tumače pitanje odgovornosti ili pozitivno ili negativno, nema odgovora između, a to je zbog uslova pripisivosti. Ovaj uslov se može protumačiti kao suviše strog.

Kada je u pitanju odgovornost države, najviše pažnje ima Nacrt članova o odgovornosti države iz 2001. godine. Smatra se da su članovi 4 i 8 deo običajnog prava i da mogu da su najznačajniji članovi kada je u pitanju odgovornost države za akte nedržavnih aktera u oružanom sukobu. Radnja nedržavnog aktera može se pripisati državi ako je država imala dovoljno veza sa akterom prema članu 4 , ili sa operacijom tokom koje je izvršena radnja prema članu $8 .{ }^{45}$

Međunarodni sud pravde se prvi pozabavio problemom odgovornosti države za radnje nedržavnih aktera tako što je stvorio novi pravni standard - test efektivne kontrole. To je učinjeno u slučaju vojnih i paravojnih aktivnosti protiv Nikaragve 1984. godine, kada je Nikaragva podnela tužbu protiv Sjedinjenih Američkih Država jer su podržavali Kontras, nedržavnu naoružanu grupu koja je dejstvovala u Nikaragvi protiv socijalističke Sandinistine vladavine. Sud je utvrdio da su SAD podržavale Kontras. Sud je zaključio da je neophodno utvrditi da je država imala efektivnu kontrolu kako bi se uspostavila njena odgovornost. Standard efektivne kontrole znači da je privatno ponašanje

\footnotetext{
${ }^{44}$ Katharine Fortin, "The Relevance of Article 9 of the Articles on State Responsibility for the Internationally Wrongful Acts of Armed Groups", in: James Summers and Alex Gough (eds), Non-State Actors and International Obligations (Creation, Evolution and Enforcment), Leiden, Brill Nijhoff, 2018, pp. 372-374.

${ }^{45}$ Oona A. Hathaway, Emily Chertoff, Lara Domínguez, Zachary Manfredi and Peter Tzeng, "Ensuring Responsibility: Common Article 1 and State Responsibility for Non-State Actors", Texas Law Review, Vol. 95, 2017, pp. 546-547.
} 
finansirano, planirano ili na drugi način sprovedeno od strane države, ali je neophodno da je država imala visok nivo kontrole u odnosu na svaku operaciju u kojoj se kršenje pojavilo. Ovaj standard se pojavio i u slučaju Primene Konvencije o sprečavanju i kažnjavanju zločina genocida u presudi iz 2007. godine kada je sud potvrdio test efektivne kontrole i primenio ga tako da je indikovao utvrđivanje visokog stepena dokazne vrednosti kako bi se ostvarila pripisivost. Postavilo se pitanje mogu li radnje vojnih i paravojnih grupacija koje su dejstvovale na području SFRJ da se pripišu vladi? Sud je utvrdio da je Bosna i Hercegovina dokazala da je SRJ, kao sukcesor SFRJ, podržavala Vojsku Republike Srpske i da su njene radnje $u$ Srebrenici bile genocidne, ali nije dokazala da su te radnje mogle da se pripišu SRJ na osnovu testa efektivne kontrole. ${ }^{46}$

Pitanje odgovornosti države ponovo se postavilo pred žalbeno veće Haškog tribunala kroz pitanje pripisovosti države u slučaju Tadić. U ovom slučaju, tužilac je podneo tužbu protiv Duška Tadića, bosanskog Srbina, političara i člana paramilitarne grupacije za teška kršenja međunarodnog humanitarnog prava. Žalbeno veće je odbilo da primeni test efektivne kontrole na činjenice ovog slučaja. Istaklo je da je svrha člana 8 Nacrta članova u tome da spreči države da izbegavaju međunarodne odgovornosti za radnje koje su privatni pojedinci preuzeli, koje nisu preduzeli državni zvaničnici. Tako je uveden standard sveobuhvatne kontrole. Dakle, nije dovoljno samo davati opremu i finansirati grupu, već je neophodno i koordinisati i pomagati generalni plan vojnih akcija. $\mathrm{Na}$ osnovu ovoga je utvrđena odgovornost Tadića za kršenja humanitarnog prava i Ženevske konvencije, zajedničkog člana 2, kao i člana 2 Statuta Haškog tribunala. Ipak, ovaj standard nije šire prihvaćen. ${ }^{47}$

Zajednički član 1 Ženevskih konvencija može biti izvor odgovornosti države za akte nedržavnih aktera, i na taj način može pomoći u definisanju pripisivosti. Naime, 2016. godine Međunarodni komitet Crvenog krsta prvi put je dao revidirane komentare na Ženevske konvencije u kojima se šire pristupa tumačenju zajedničkog člana 1. Smatra se da ovaj član u sebi sadrži i negativnu obavezu (da se ne ohrabruje, pomaže ili asistira u

\footnotetext{
${ }^{46}$ Ibid., pp. 548-550.

${ }^{47}$ Ibid., pp. 554-556.
} 
kršenju konvencija), ali i pozitivnu obavezu državama ugovornicama da moraju činiti sve što je razumno u njihovoj moći kako bi sprečili kršenja i kako bi ih okončali. Na ovaj način uveden je standard dužne pažnje - due diligence u pitanje odgovornosti države. ${ }^{48}$

Praksa međunarodnih krivičnih tribunala ima određenu težinu i pred domaćim sudovima, a upravo pitanje pomaganja i podržavanja može biti relevantno i u kontekstu korporativne odgovornosti za učešće u kršenju ljudskih prava. Vodeći principi UN za biznis i ljudska prava, koje je jednoglasno uvojio Savet za ljudska prava 2011. godine, kažu da upravo težina prakse u međunarodnom krivičnom pravu indicira da su relevantni standardi za pomaganje i podržavanje svesno davanje praktične pomoći ili ohrabrenja koje je imalo substantivni efekat u izvršavanju krivičnog dela.

Kada je u pitanju odgovornost države u međunarodnom krivičnom pravu, Komisija za međunarodno pravo je u svom Nacrtu članova o odgovornosti država rekla da će ona biti odgovorna za međunarodno pogrešno postupanje pojedinaca ili grupa, bez znanja ili prisvajanja takvog ponašanja kao sopstvenog, ako su te osobe postupale po njenim instrukcijama ili pod kontrolom te države. Takođe, pod istim uslovima biće odgovorna i država koja upravlja i kontroliše ponašanje druge države koja je učinila protipravni akt, kao i ukoliko pomaže drugoj državi. Dakle, da bi država bila odgovorna za pomoć nedržavnim akterima koji su počinili ratne zločine, traži se da je država kontrolisala, davala uputstva ili upravljala tim grupama u vezi sa konkretnim ponašanjem. Takođe, država može biti odgovorna i u odsustvu pomoći, ako je nezakonito ponašanje učinjeno pod njenom kontrolom ili uputstvom. Termin kontrola je razrađen u praksi Međunarodnog suda pravde i Međunarodnog krivičnog tribunala za bivšu Jugoslaviju. U slučaju Nikaragva protiv SAD, kao što je rečeno, Međunarodni sud pravde morao je da utvrdi vezu između Sjedinjenih Država i Kontrasa, oružane grupe koja se borila protiv Nikaragve kako bi utvrdila da ponašanja kontrasa mogu da se pripišu SAD.$^{49}$

48 Ibid., pp. 565.

49 Shane Darcy, "Assistance, direction and control: Untangling international judicial opinion on individual and State responsibility for war crimes by non-State actors", op. cit., pp. 258-260. 
Odgovornost države i individualna krivična odgovornost su odvojene, ali se međusobono ne isključuju, te se mogu pojaviti simultano za radnje vezane za ratne zločine. Često je to u domenu sprečavanja i kažnjavanja zločina. ${ }^{50}$

\section{ZAKLJUČAK}

Uzevši u obzir globalizaciju i razvoj savremenog međunarodnog prava ne može se ignorisati postojanje nedržavnih aktera i njihov uticaj na različite pravne institute. Na primer, pojavljuju se u oblasti ljudskih prava, diplomatskog i konzularnog, krivičnog i humanitarnog prava. Ovaj njihov uticaj nije zaobišao ni institut odgovornosti. Više se i ne osporava postojanje odgovornosti (barem nekih) nedržavnih aktera, a to je doprinelo i tome da se razmatra postojanje pojma međunarodne odgovornosti, mnogo šireg od dosadašnje odgovornosti koja se odnosila na države. Dakle, uzajaman je uticaj između ovih subjekata i instituta.

Odgovornost se ukratko može predstaviti kao ostvarivanje principa „svakome po zasluzi“ - ko prekrši, biće kažnjen i moraće da nadoknadi štetu. Međutim, kako to često biva, nije svako dobio svoj deo kolača. Konkretno, međunarodne organizacije su dobile Nacrt članova o odgovornosti 2011. godine i time postale, pored države, jedini subjekti čiju odgovornost je uređivala Komisija za međunarodno pravo. Nažalost, brojne su kritike na račun ovih članova koje i danas možemo čuti. One su dovele do toga da se ovaj Nacrt ni ne primenjuje, a male su šanse da će ikada biti usvojen u formi konvencije. Zatim, odgovornost transnacionalnih kompanija ograničena je na oblast ljudskih prava, gde su se javili određeni regulatorni akti. Pored toga, pojam korporativne socijalne odgovornosti je izuzetno zanimljiv, a slabo analiziran u našoj literaturi. Uređivanje odgovornosti transnacionalnih kompanija počiva na instrumentima mekog prava i čini se da će tako i ostati. Da li bi bilo bolje da Komisija za međunarodno pravo uredi i ovu oblast? Čini mi se da je neuspeh koji je imala sa uređivanjem odgovornosti međunarodnih organizacija ostavio traga, te da će se Komisija ovde zaustaviti kada je u

${ }^{50}$ Ibid., pp. 266-267. 
pitanju sam institut odgovornosti, barem za sada. Odgovornost pojedinca i oružanih grupa zajedno su analizirani u ovom radu. Suvišno bi bilo detaljnije analizirati na ovom mestu individualnu krivičnu odgovornost, jer je tome posvećeno mnogo pažnje u literaturi. Naizgled je ta situacija za sada zadovoljavajuća, mada postoje određena pitanja za dalju analizu. Na primer, da li bi i pod kojim uslovima mogla da se ustanovi kolektivna odgovornost za međunarodna krivična dela? Čini se da bi to često bilo poštenije, ali da li postoji kolektivna krivica?

Na kraju, bilo bi zanimljivo videti Međunarodni sud pravde i mnoge međunarodne sudove, tribunale i arbitraže da primenjuju ove principe u svojim presudama. To bi moglo doprineti mnogo širem razvoju ove veoma važne oblasti. Možda bi se napokon i utvrdilo pitanje odgovornosti nevladinih organizacija, za koju već decenijama vlada dilema kako odgovaraju, kome i za koje akte.

\section{LITERATURA}

Aaronson, Susan Ariel and Higham, Ian, "Putting the Blame on Governments: Why Firms and Governments Have Failed to Advance the Guiding Principles on Business and Human Rights", in: Kurt Mills and David Jason Karp (eds), Human Rights Protection in Global Politics, Palgrave Macmillan, London, 2015, pp. 113-136.

Blokker, Niels M., "Preparing articles on responsibility of international organizations: Does the International Law Commission take international organizations seriously? A mid-term review" in: Jan Klabbers and Asa Wallendahl (eds), Research handbook on the law of international organizations, Edward Elgar Pub, Cheltenham, 2011, pp. 313-341.

Bruneé, Jutta, "International Legal Accountability Through the Lens of the Law of State Responsibility", Netherlands Yearbook of International Law, Vol. 36, pp. 3-38.

Clapham, Andrew , "The Rights and Responsibilities of Armed Non-State Actors: The Legal Landscape \& Issues Surrounding Engagement", dostupno na SSRN: https://ssrn.com/abstract=1569636. ili http://dx.doi.org/10.2139/ssrn.1569636, 10/05/2020. 
D'Aspremont, Jean, Nollkaemper, André, Plakokefalos, Ilias, Ryngaert, Cedric, "Sharing Responsibility Between Non-State Actors and States in International Law: Introduction", Netherlands International Law Review, 62, 2015, pp. 49-67.

Darcy, Shane, "Assistance, direction and control: Untangling international judicial opinion on individual and State responsibility for war crimes by non-State actors", International Review of the Red Cross, Vol. 96, pp. 243-273.

Daugirdas, Kristina, "Reputation and the Responsibility of International Organizations", The European Journal of International Law, Vol. 25, no. 4, pp. 991-1018.

Draft articles on the responsibility of international organizations, Yearbook of the International Law Commission, 2011, vol. II, Part Two.

Draft Articles on Responsibility of States for Internationally Wrongful Acts, Yearbook of the International Law Commission, 2001, vol. II (Part Two).

Fortin, Katharine, "The Relevance of Article 9 of the Articles on State Responsibility for the Internationally Wrongful Acts of Armed Groups", in: James Summers and Alex Gough (eds), Non-State Actors and International Obligations (Creation, Evolution and Enforcment), Leiden, Brill Nijhoff, 2018, pp. 371-387.

Guay, Terrence, Doh, Jonathan P., Sinclair, Graham, “Non-governmental Organizations, Shareholder Activism, and Socially Responsible Investments: Ethical, Strategic, and Governance Implications", Journal of Business Ethics, 52, pp. 125-139.

Hathaway, Oona A., Chertoff, Emily, Domínguez, Lara , Manfredi, Zachary and Tzeng, Peter, "Ensuring Responsibility: Common Article 1 and State Responsibility for Non-State Actors", Texas Law Review, Vol. 95, 2017, pp. 539-590.

Karp, David Jason, "The Concept of Human Rights Protection and the UN Guiding Principles on Business and Human Rights", in: Kurt Mills and David Jason Karp (eds), Human Rights Protection in Global Politics, Palgrave Macmillan, London, 2015, pp. 137-158. 
Klabbers, Jan, "Issues of responsibility", chapter in An Introduction to International Organizations Law, Cambridge, Cambridge University Press, 2015, pp. 306-339.

Klabbers, Jan, "Reflections on Role Responsibility: The Responsibility of International Organizations for Failing to Act", The European Journal of International Law, Vol. 28, no. 4, pp. 1133-1161.

Kolb, Robert, The International Law of State Responsibility: An Introduction, Edward Elgar Publishing Limited, Cheltenham, 2017, pp. 1-33.

Kreća, Milenko, Međunarodno javno pravo, Univerzitet u Beogradu Pravni fakultet, Centar za izdavaštvo, Beograd, 2019.

McCorquodale, Robert, "The Individual and the International Legal System" in: Malcom Evans (ed), International Law, Oxford, Oxford University Press, 2006, pp. 307-332.

Nuzov, Ilya, "Post-Conflict Justice: Extending International Criminal Responsibility to Non-State Entities" in: Ezequiel Heffes, Marcos D. Kotlik, Manuel J. Ventura (eds), International Humanitaran Law and Non-State Actors, The Hague, Springer, 2020, pp. 229-264.

Pariotti, Elena, "International Soft Law, Human Rights and Non-state Actors: Towards the Accountability of Transnational Corporations?", Human Rights Review, 10, pp. 139-155.

Pellet, Alain, "International Organizations Are Definitely Not States. Cursory Remarks on the ILC Articles on the Responsibility of International Organizations" in: Maurizio Ragazzi (ed), Responsibility of International Organizations, Essays in Memory of Sir Ian Brownlie, Martinus Nijhoff Publishers, Leiden, Boston, 2013, pp. 41-54.

Reinisch, August, "The Changing Internantional Legal Framework for Dealing with Non-State Actors", in: P. Alston (ed), Non-State Actors and Human Rights, Oxford, Oxford University Press, 2005, pp. 37-89. Roeben, Volker, "Responsibility in International Law", Max Planck Yearbook of International Law, Vol. 16, pp. 99-158.

Ryngaert, Cedric, “The European Court of Human Rights'approach to the Responsibility of Member States in connection with acts of 
International Organizations", International and Comparative Law Quarterly, Vol. 60, No. 4, pp. 997-1016.

Shaw, Malcolm, International Law, Cambridge University Press, Cambridge, 2014.

Weissbrodt, David, "Roles and Responsibilities of Non-State Actors" in: Dinah Shelton (ed), The Oxford Handbook on International Human Rights Law, pp. 558-571.

\section{RESPONSIBILITY OF NON-STATE ACTORS}

Abstract: Non-state actors are gaining increasing importance in modern international law, especially since there is more and more talk about the crisis of states as subjects of international law. As participants in events within the international community, they are responsible for the acts they commit. Accountability in international law is one of the most important institutes, and therefore this area never loses interest. And some international bodies, such as the United Nations Commission on International Law and the Association for International Law, recognize the importance of this topic. The report of the Special Rapporteur of the Secretary-General on the need to introduce the responsibility of non-state actors is paying particular attention to this topic. That is why the UN Commission on International Law adopted a draft article on the responsibility of international organizations, and great attention is dedicated to individual criminal responsibility. In this paper, in addition to these important issues, the author will present the responsibility borne by transnational companies and non-governmental organizations. The aim of this paper is to provide an overview of the current situation in these areas, as well as to make proposals for possible further ventures in terms of codification.

Keywords: responsibility, non-state actors, international organizations, an individual, armed groups, transnational corporations. 